\title{
Medicated Collar Dosage Form
}

National Cancer Institute

\section{Source}

National Cancer Institute. Medicated Collar Dosage Form. NCI Thesaurus. Code C149649.

Solid preparation for veterinary use consisting of a matrix impreg nated with active substance(s), which is worn around the animal's neck. The active substance(s) are released by diffusion, by mechanical means or by vaporization over a period of time. 